\title{
Biosynthesis, Metabolism and Function of Auxin, Salicylic Acid and Melatonin in Climacteric and Non-climacteric Fruits
}

OPEN ACCESS

Edited by:

Antonio Ferrante,

University of Milan, Italy

Reviewed by:

Ana Margarida Fortes

Universidade de Lisboa, Portugal María Serrano,

Universidad Miguel Hernández de Elche, Spain

*Correspondence:

Sergi Munné-Bosch smunne@ub.edu

Specialty section: This article was submitted to Crop and Product Physiology, a section of the journa

Frontiers in Plant Science

Received: 16 December 2018 Accepted: 28 January 2019

Published: 18 February 2019

Citation:

Pérez-Llorca M, Muñoz P, Müller M and Munné-Bosch S (2019)

Biosynthesis, Metabolism and Function of Auxin, Salicylic Acid and Melatonin in Climacteric and Non-climacteric Fruits.

Front. Plant Sci. 10:136. doi: 10.3389/fp/s.2019.00136

\author{
Marina Pérez-Llorca1 , Paula Muñoz ${ }^{1,2}$, Maren Müller ${ }^{1,2}$ and Sergi Munné-Bosch ${ }^{1,2 *}$ \\ ${ }^{1}$ Department of Evolutionary Biology, Ecology and Environmental Sciences, University of Barcelona, Barcelona, Spain, \\ ${ }^{2}$ Institute for Research on Nutrition and Food Safety, University of Barcelona, Barcelona, Spain
}

Climacteric and non-climacteric fruits are differentiated by the ripening process, in particular by the involvement of ethylene, high respiration rates and the nature of the process, being autocatalytic or not, respectively. Here, we focus on the biosynthesis, metabolism and function of three compounds (auxin, salicylic acid and melatonin) sharing not only a common precursor (chorismate), but also regulatory functions in plants, and therefore in fruits. Aside from describing their biosynthesis in plants, with a particular emphasis on common precursors and points of metabolic diversion, we will discuss recent advances on their role in fruit ripening and the regulation of bioactive compounds accumulation, both in climacteric and non-climacteric fruits.

Keywords: auxin, biotrophs, defenses, fruit ripening, maturation, melatonin, post-harvest, salicylates

\section{INTRODUCTION}

Correct progression of fruit ripening is essential to achieve both optimal fruit quality and long shelf life, important traits that determine price markets and final profits. However, ripening is a complex process where many factors are involved, including hormonal control, which regulates biochemical and physiological changes that give final organoleptic and nutritional fruit properties. Traditionally, fleshy fruits have been classified according to there ripening process into climacteric and nonclimacteric fruits. Climacteric fruits such as tomatoes or bananas require an upsurge in respiration rate and ethylene production to unleash the ripening process in an autocatalytic response (Barry and Giovannoni, 2007; Liu et al., 2015). Antagonistically, non-climacteric fruits like citrus fruits or grapes do not exhibit a burst neither in ethylene nor respiration prior to ripening onset, and in these fruits, ripening is mainly controlled by progressive accumulation of the phytohormone abscisic acid (ABA; Rodrigo et al., 2006; Castellarin et al., 2011). Nevertheless, new studies are reinforcing the idea that the ripening process is not only governed by the production of one phytohormone but rather seeming to be the result of a controlled hormonal balance (Symons et al., 2012; Teribia et al., 2016; Li et al., 2019).

Auxins, salicylic acid (SA), and melatonin are phytohormones involved in the signaling and regulation of many crucial processes in plants. Auxins have been widely described as growth and development regulators with multiple functions in plants (see Taylor-Teeples et al., 2016); SA triggers the defense response against biotrophic and hemi-biotrophic pathogens (Loake and Grant, 2007) as well as having an important role under abiotic stress (Dong et al., 2014; Wani et al., 2017), flowering and cell cycle control (Carswell et al., 1989; Eberhard et al., 1989, respectively); 
and melatoninhas not only been found to have auxin-like functions (Chen et al., 2009; Zuo et al., 2014; Wen et al., 2016) but it also has been suggested to act as a potential antioxidant in some plants (Arnao and Hernández-Ruiz, 2015) and a regulator of plant responses to pathogens (Chen et al., 2018). Interestingly, these three hormones share a common precursor - chorismate -, thus a metabolic cross-talk occurs between them, and a number of genes must be finely regulated to divert chorismate metabolism toward these compounds. During the past few years, several reviews have addressed the biosynthesis and role of auxin (Paul et al., 2012), SA (Asghari and Aghdam, 2010) and melatonin (Feng et al., 2014; Arnao and Hernández-Ruiz, 2018) in fruits. However, their biosynthesis and functions have mostly been described separately. Here, we will discuss the common and differential aspects of the biosynthesis, metabolism and function of auxin, SA and melatonin in the growth and ripening of climacteric and non-climacteric fruits. An emphasis will be put on metabolic diversion key points in their biosynthesis from chorismate, the regulatory role during the ripening of climacteric and nonclimacteric fruits, and their role in the modulation of the biosynthesis of bioactive compounds, which largely determines fruit quality.

\section{CHORISMATE-DERIVED PHYTOHORMONES}

Chorismate is the final product of the shikimate pathway and plays a key role in the biosynthesis of phytohormones (Figure 1). Chorismate gives rise to aromatic amino acids, including tryptophan, and through several reactions, including the conversion of tryptophan to indole-3-pyruvic acid by the tryptophan aminotransferase (TA); it can generate the auxin indole-3-acetic acid (IAA). TA has been proposed as a universal key enzyme to IAA biosynthesis not only in vegetative organs (Enríquez-Valencia et al., 2018) but also in the development of reproductive organs (Reyes-Olalde et al., 2017), including fruit growth and ripening (Estrada-Johnson et al., 2017). By contrast, when isochorismate synthase (ICS) is activated, chorismate can be converted into isochorismate and the latter can be transformed into SA. Despite the fact that this pathway was first identified in bacteria, it is also currently well established in plants (Wildermuth et al., 2001; Uppalapati et al., 2007; Catinot et al., 2008; Garcion et al., 2008; Abreu and Munné-Bosch, 2009). Finally, tryptophan can turn into tryptamine by the enzyme tryptophan decarboxylase (TDC). Although this is another of the multiple routes of IAA biosynthesis (tryptamine turns into indole-3-acetaldehyde and later into IAA), TDC has also been proposed to be the first rate-limiting enzyme in the melatonin pathway (Kang et al., 2007). TDC was first identified in the Apocynaceae family (De Luca et al., 1989) to be later described in a number of plant systems (Byeon et al., 2012, 2014; Zhao et al., 2013; Wei et al., 2018). After decarboxylation, tryptamine is converted into serotonin by the tryptamine-5-hydroxylase, and then serotonin transforms into $\mathrm{N}$-acetyl-serotonin to finally yield melatonin in the cytosol (Figure 1).
Key-diverting enzymes that lead to the synthesis of the chorismate-pathway hormones have been recently identified in fleshy fruits (Figure 1). ICS, which expression has been shown to be crucial for biotic stress tolerance (Garcion et al., 2008; Zeng and $\mathrm{He}, 2010$ ), has been identified in tomatoes and apples. Zhu et al. (2016) reported the overexpression of ICS1 (isochorismate synthase 1) under cold storage conditions in tomato, while Zhang et al. (2017) found activation of a transcription factor involved in the pathogen-related SA signaling pathway inducing ICS expression in apples. Enhanced TDC activity has been reported to occur in unripe pepper fruit upon infection by pathogens through increased TDC1 and TDC2 expression (Park et al., 2013) - and in the growth stage in mulberry fruit (Wang et al., 2016). Finally, TA has been identified in grapevine, both at preand véraison (Böttcher et al., 2013; Gouthu and Deluc, 2015, respectively) as well as during strawberry ripening (EstradaJohnson et al., 2017). It is noteworthy, however, that the genes and enzymes described in climacteric fruits (i.e., ICS) have not been identified in non-climacteric fruits (i.e., TDC and TA) and vice versa; hence, further studies are imperative to fill these knowledge gaps and better understand how these diversion points are jointly regulated during fruit ripening.

\section{ROLE OF CHORISMATE-DERIVED PHYTOHORMONES IN CLIMACTERIC AND NON-CLIMACTERIC FRUITS}

Unraveling the mechanisms of fruit development has been one of the major challenges in recent agronomy research for its economic implications. In this context, phytohormones have been pointed out as accountable drivers of fruit ripening, specially ethylene and $\mathrm{ABA}$ in climacteric and non-climacteric fruits, respectively. However, that these phytohormones could regulate fruit development alone was soon proven to be far too simple. After extensive research and with the improvement in analytical chemistry and molecular techniques, several other hormones have been confirmed as potential regulators of fruit development and ripening, including chorismate-derived phytohormones.

\section{Auxins Cross-Talk With Other Hormones During Fruit Set, Growth and Ripening}

Auxins are a group of plant hormones that play an essential role in fruit development, both exerting their own influence and modulating expression of other phytohormones. Endogenous contents of IAA are particularly high at fruit set and during initial growth developmental stages, after which IAA amounts tend to decline before ripening onset, both in climacteric (Zaharah et al., 2012) and non-climacteric fruits (Symons et al., 2012; Teribia et al., 2016), with apparently some exceptions, like peaches (Tatsuki et al., 2013) and some plum varieties (El-Sharkawy et al., 2014; Figure 2A). It has been demonstrated that IAA is involved in fruit set initiation in combination with gibberellins (Mezzetti et al., 2004; Serrani et al., 2010; Bermejo et al., 2018; Hu et al., 2018). Impairment of IAA biosynthesis or signaling generally leads to fruit parthenocarpy, although it may also result in 


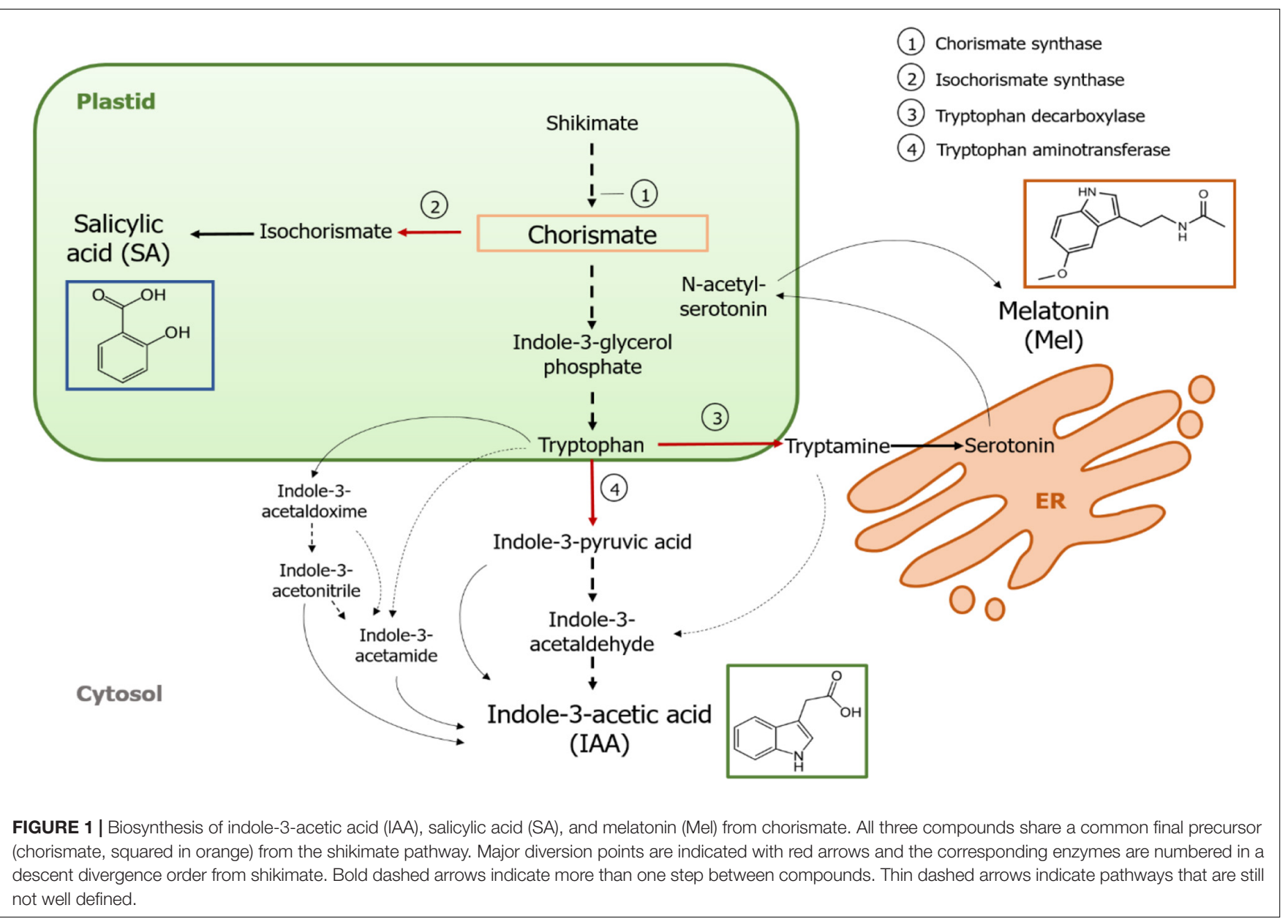

abnormal ripening in some fruits (Wang et al., 2005; Liu J. et al., 2018; Reig et al., 2018). High contents of IAA at initial stages of fruit development promote fruit growth due to auxin implication in cell division in combination with cytokinins and in the control of cell expansion in combination with gibberellins (Liao et al., 2018). During this period, hormonal crosstalk between auxins and gibberellins additionally allows normal fruit shaping in a fine-tuned regulation mediated by Auxin Response Factors (ARFs; Liao et al., 2018; Liu S. et al., 2018).

Reductions of endogenous IAA contents have been reported to occur before the onset of ripening in several fruits. These reductions have been related to IAA conjugation with aspartic acid (IAA-Asp) by IAA-amido synthetases, $\mathrm{GH}_{3-1}$ and $\mathrm{GH}_{3-2}$ (Figure 2C). Indeed, $\mathrm{GH}_{3-1}$ and $\mathrm{GH}_{3-2}$ showed higher expression during early fruit development and most particularly during ripening initiation both in climacteric fruits, such as tomatoes (Sravankumar et al., 2018) and apples (Onik et al., 2018), as well as in non-climacteric fruits, like grape berries (Böttcher et al., 2010, 2011) and raspberries (Bernales et al., 2019). Interestingly, grape berries showed enhanced $\mathrm{GH}_{3-1}$ expression after ABA and ethephon application, which could explain the involvement of ethylene in the control of IAA contents after the onset of ripening, even in non-climacteric fruits (Böttcher et al., 2010). In fact, several studies highlight the tight interaction between auxins and ethylene in fruit ripening, with a reciprocal influence between them (Tadiello et al., 2016a; Busatto et al., 2017). For climacteric fruits, increased contents of IAA are necessary to activate expression of ACC synthase genes (ACS), encoding ACC synthase, which, in turn, will lead to ethylene production triggering the ripening process (Figure 2C; Tatsuki et al., 2013). Fruits like tomatoes (Li et al., 2016) or bananas (Choudhury et al., 2008), which usually experience reduced IAA contents prior to the onset of ripening, show a ripening delay when IAA or analogs are exogenously applied, while fruits like peaches, whose IAA contents increase progressively until fully ripen, show accelerated ripening when auxins are applied (Tadiello et al., 2016b). Therefore, a tight, complex and differential regulation of auxin-ethylene interactions must exist in various fruits during preharvest ripening. Furthermore, IAA contents decrease before ripening onset in some non-climacteric fruits to de-repress 9-cis-epoxycarotenoid dioxygenase (NCED) and start ABA synthesis (Figure 2C; Jia et al., 2016). Interestingly, this process is also mediated by IAA conjugation through enhanced $\mathrm{GH}_{3-1}$ activity (Böttcher et al., 2010). Nevertheless, Estrada-Johnson et al. (2017) showed that, although IAA contents decrease during strawberry ripening, expression of FaAux/IAA and FaARF gene families are induced in red receptacles, suggesting the involvement of auxin signaling in fully ripen fruits. 
A

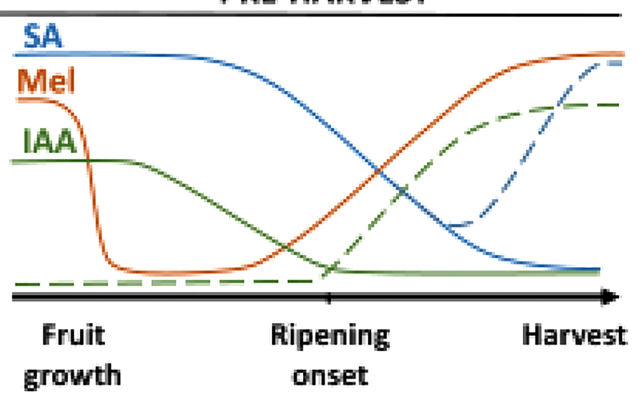

B

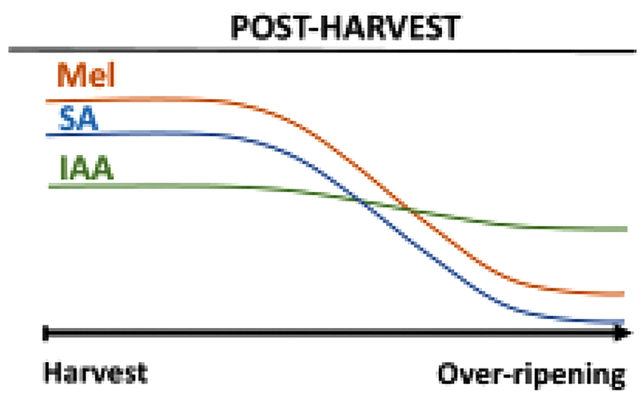

C

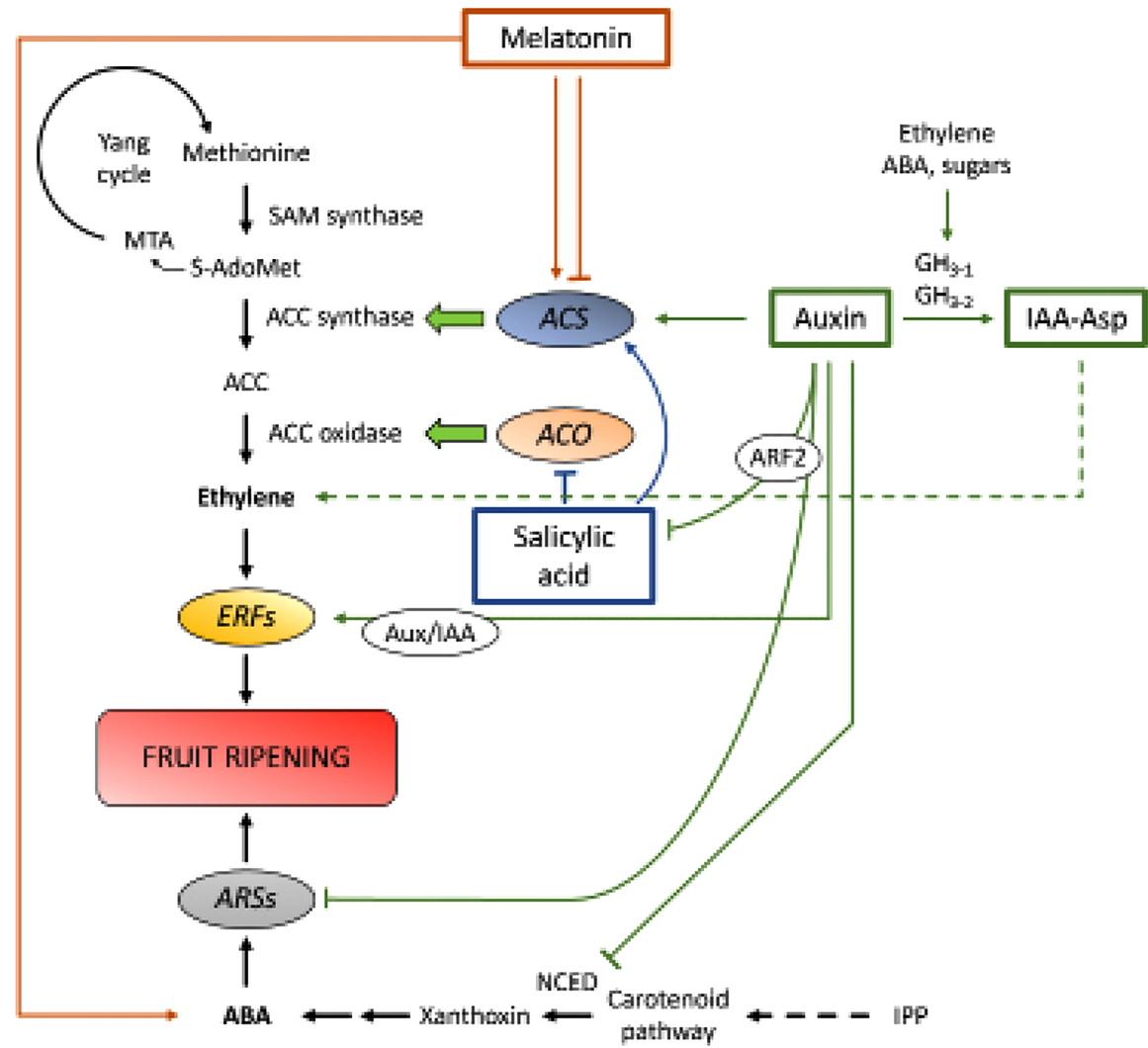

FIGURE 2 | Role of IAA, SA, and Mel during the development of climacteric and non-climacteric fruits. Model summarizing the interactions of IAA, SA, and Mel during the ripening of climacteric and non-climacteric fruits during (A) pre- and (B) post-harvest. Dashed lines indicate alternative dynamics of phytohormone contents in some fruits (see text for discussion). (C) Overview of the interaction of IAA, SA, and Mel with ethylene and abscisic acid (ABA) biosynthesis in climacteric and non-climacteric fruits. Auxin is a positive regulator of ethylene biosynthesis by the activation of ACC synthase genes (ACS) and inducing the expression of Ethylene Responsive Factors (ERFs). Auxin also represses ABA production by 9-cis-epoxycarotenoid dioxygenase (NCED) repression and inhibiting ABA-responsive stress genes (ARS) by the ARF2 protein. Endogenous IAA contents can be reduced by $\mathrm{GH}_{3}$ proteins, the synthesis of which is promoted by ethylene, $\mathrm{ABA}$ and sugars. Discontinuous line indicates the possible role of IAA by IAA-Asp as a ripening factor enhancing ethylene in some fruits. Melatonin enhances ABA and ethylene production, although ACS can be inhibited depending on melatonin contents. SA acts as an inhibitor of ethylene repressing ACC oxidase (ACO) genes, although it can promote the expression of ACS. MTA, 50-methylthioadenosine; S-AdoMet, S-adenosyl-methionine; SAM synthase, S-adenosyl-methionine synthase; ACC, 1-aminocyclopropane-1-carboxylic acid; IPP, isopentenyl diphosphate.

During post-harvest, auxin contents usually remain invariant or tend to decrease due to oxidative processes that may give rise to small, but progressive reductions in the endogenous contents of IAA (Figure 2B). Auxin treatments after harvest delay over-ripening in some fruits (Chen et al., 2016; Moro et al., 2017) and increase the contents of some organic acids, maintaining fruit acidity (Li et al., 2017), thus suggesting auxin also 
plays a significant role in the control of fruit ripening during post-harvest.

\section{Multiple Roles of Salicylic Acid During Fruit Development and Ripening}

Salicylic acid is another chorismate-derived phytohormone that has been mostly related to its protective effect under biotic stress to control preharvest and post-harvest losses derived from pathogen fruit infection (Babalar et al., 2007; Cao et al., 2013). In general, endogenous contents of free SA are higher at the beginning of fruit development and then decrease progressively (Oikawa et al., 2015). Lu et al. (2015) reported a secondary increase in SA during the second growth phase of peach fruits. Exogenous application of SA in bananas delayed the ripening process reducing the respiratory burst and the pulp to peel ratio, as well as decreasing activity of enzymes related to cell wall degradation and antioxidant system (Srivastava and Dwivedi, 2000). Moreover, treatment of sweet cherry trees with salicylic and acetylsalicylic acid (ASA) enhanced weight, firmness and color of cherries at commercial stage (Giménez et al., 2014). Exogenous application of SA or metyl salicylate (MeSA) during post-harvest, delayed over-ripening in fruits like kiwis (Zhang et al., 2003), and sweet cherries (Valero et al., 2011). Furthermore, treatments with salicylic or ASA alleviated chilling injury of pomegranates (Sayyari et al., 2011), tomatoes (Aghdam et al., 2014), and avocados (Glowacz et al., 2017). SA also interacts with ethylene through inhibition of ACC oxidase (ACO) expression (Shi and Zhang, 2012). Surprisingly, increased contents of ACS expression in pears are also found after SA application in a dose-regulated manner (Shi et al., 2013; Shi and Zhang, 2014). Therefore, regulation of ethylene production dependent on SA is finely regulated (Figure $2 \mathrm{C}$ ).

\section{Melatonin: An Emerging Regulator for the Control of Fruit Development}

Melatonin is also a plant hormone from the chorismate-derived pathway that has gained much attention in the recent years (Hernández-Ruiz et al., 2005; Arnao and Hernández-Ruiz, 2018; Sharif et al., 2018). Recently, melatonin has been pointed out as an important factor for fruit set, in a similar way to IAA effects (Figure 2A; Liu S. et al., 2018). Besides, circadian production of this phytohormone has been observed (Kolár et al., 1997). During on-tree ripening, grapes treated with melatonin showed higher synchronicity and increased weight when fully ripens (Meng et al., 2015). Moreover, another recent study by Xu et al. (2018) described that melatonin could promote grape berry ripening through its interaction with $\mathrm{ABA}$ and ethylene, as well as hydrogen peroxide. It has been demonstrated that melatonin confers chilling tolerance during fruit cold storage, which appears to be mostly related to its antioxidant activity (Cao et al., 2018; Aghdam et al., 2019). During post-harvest, tomatoes showed increased ethylene emission after application of melatonin at $50 \mu \mathrm{M}$ (Sun et al., 2015), contrary to pears, where exogenous application of melatonin at $100 \mu \mathrm{M}$ inhibited ethylene production (Zhai et al., 2018), or banana fruits, where melatonin at 50-200 $\mu \mathrm{M}$ inhibited the expression of ACS and
ACO (Figure 2C; Hu et al., 2017). Although different effects of melatonin application may be related to a dosage effect, further research is needed to better understand the role of melatonin in the control of fruit development.

\section{Cross-Talk of Chorismate-Derived Phytohormones in the Control of Fruit Development}

Hormonal crosstalk between chorismate-derived phytohormones has been shown to occur during fruit development and ripening. Breitel et al. (2016) found that auxins can interact with SA through ARF2 (Figure 2C) and that overexpression of $A R F 2$ in tomato resulted in lower contents of $\mathrm{SA}$ and a significant ripening delay. This indicates that auxins might be limiting SA production during fruit development, which might explain a trade-off between fruit growth (mediated by auxin) and activation of biotic defenses (mediated by SA). Moreover, exogenous application of SA on papaya fruits resulted in an altered expression of several IAA genes, some of them being down-regulated while others up-regulated (Liu et al., 2017). In this case, results were inconclusive of what really occurs endogenously in the putative cross-talk between auxin and SA during fruit ripening and further research is required in this and other climacteric fruits. In any case, it is clear that IAA and SA are closely related, not only metabolically but also functionally. Finally, several studies have reported the influence of melatonin on IAA and SA biosynthesis and/or signaling (reviewed in Arnao and Hernández-Ruiz, 2018), although to our knowledge, none of these studies was performed neither in climacteric nor in non-climacteric fruits.

\section{MODULATION OF BIOACTIVE COMPOUNDS BIOSYNTHESIS BY CHORISMATE-DERIVED PHYTOHORMONES}

Bioactive compounds (including phenolic compounds, isoprenoids, and antioxidant vitamins) have not only been widely investigated as responsible for specific organoleptic properties of foods, but also for their protective effects in human cells against oxidative processes in the development of neurodegenerative and cardiovascular diseases and certain type of cancer (Liu et al., 1999; Mueller et al., 2010; Sturgeon and Ronnenberg, 2010; Björkman et al., 2011). Phenolic compounds contribute significantly to imparting specific flavors, such as tannins - responsible for the bitterness or astringency taste of certain fruits, and colors, such as anthocyanin pigments responsible for red, blue and purple fruit colors (Croteau et al., 2000). The relevance of phenolic compounds for human consumption has been associated with a protective effect against oxidative processes in relation to cardiovascular and central nervous system health as well as a reduced risk for cancers of the gastrointestinal tract (Björkman et al., 2011). Carotenoids, tetraterpenes belonging to isoprenoids, play a role in the protection against photo-oxidative processes and as organic 
pigments; they are responsible for the orange-yellow color of fruits (Tapiero et al., 2004). Dietary carotenoids are thought to provide health benefits in decreasing the risk of eye disease and certain types of cancers due to their role as antioxidants (Johnson, 2002). Vitamins C and E, including ascorbic acid and tocopherols, respectively, are essential nutritional quality factors in fruits with many biological activities in humans (Miret and Müller, 2017). Considering the relevant role of all these bioactive compounds as health promoting compounds in fruits, the modulation of their accumulation is of paramount importance in both climacteric and non-climacteric fruits (Vasconsuelo and Boland, 2007). Most of these bioactive compounds are accumulated at high levels during fruit ripening, when less palatable green fruits converse into a nutritionally rich, colored, and tasty fruit (Daood et al., 1996; Ranalli et al., 1998; Dumas et al., 2003; Singh et al., 2011). However, once commenced, ripening cannot be stalled and generally leads to over-ripening that negatively affects the fruit quality (Kumar et al., 2014). Therefore, minimizing post-harvest fruit spoilage while obtaining high contents of bioactive compounds remains one of the biggest challenges to resolve.

Auxin has been identified as an important regulator of carotenoid biosynthesis during ripening of climacteric tomato fruits. Ripening in tomato is associated with the degradation of chlorophyll and the shift of xanthophylls to carotenes ( $\beta$-carotene and lycopene) (Fraser et al., 1994). IAA appears to delay tomato ripening by repressing ethylene and several upstream carotenoid transcripts including Psy, Ziso, Pds, Critiso as well as Chlases 1-3 and, on the other hand, promoting the accumulation of $\beta-L y c 1$ and Crtr- $\beta 1$ transcripts, resulting in higher contents of xanthophylls and chlorophyll a (Su et al., 2015). In addition, in some non-climacteric fruits such as cherry and grape berries auxin also seems to modulate anthocyanin biosynthesis and thereby control fruit ripening processes. Teribia et al. (2016) reported a negative correlation between IAA and anthocyanin contents indicating that anthocyanin accumulation starts when IAA contents decrease. Moreover, the application of the synthetic auxin-like compound benzothiazole-2-oxyacetic acid (BTOA) delayed the up-regulation of genes that promote enzymes of the anthocyanin biosynthesis such as chalcone synthase and UDP-glucose:flavonoid 3-O-glucosyltransferase in grape berries (Davies et al., 1997).

Pre- and post-harvest treatments with salicylates, including SA and its derivatives ASA and MeSA, have been reported to regulate bioactive compounds accumulation leading to improved antioxidant activity in both climacteric and non-climacteric fruits. Several fruits such as plum, cherry and apricots are known to have a short life with a rapid deterioration in quality after harvest. Therefore, there is a constant search of treatments that improve and maintain fruit quality, and especially the content of bioactive compounds with beneficial health effects. Treatments of plums with SA, ASA, and MeSA resulted in significant higher contents of ascorbic acid, anthocyanins and phenolic compounds both at harvest and after prolonged cold storage ( 40 days at $4^{\circ} \mathrm{C}$; Martínez-Esplá et al., 2017). Similar results could be observed for preharvest treatments with SA, ASA, and MeSA in sweet cherries (Giménez et al., 2014, 2015, 2017). Furthermore, post-harvest treatment with SA, ASA, or MeSA maintained total phenolic contents as well as anthocyanin contents during cold storage in pomegranate (Sayyari et al., 2011), sweet cherry (Valero et al., 2011), cornelian cherry (Dokhanieh et al., 2013), and apricot (Wang et al., 2015). These results suggest that salicylates may be involved in the activation of phenylalanine ammonia lyase, which is the main enzyme involved in the biosynthesic pathway of phenolic compounds (Martínez-Esplá et al., 2017).

Recently, melatonin has been shown to regulate fruit ripening and modulate bioactive compounds. Post-harvest treatments with melatonin in peach fruits increased chilling tolerance by activating antioxidant systems. Chilling injury occurs in peach fruits during low temperature storage (between 2 and $7.6^{\circ} \mathrm{C}$ ) characterized by flesh browning, abnormal ripening and higher sensitivity to decay (Lurie and Crisosto, 2005). Cao et al. (2018) reported that peaches treated with melatonin showed higher transcript abundance of ascorbic acid biosynthesis genes $P p G M E, P p G P P$, and $P p G L D H$ at seventh and $P p G M P H$ at the 21 st and 28th day of storage compared to control resulting in increased ascorbic acid contents. Moreover, melatonin induced increases in activities of G6PDH, SKDH and PAL, which are the essential enzymes for phenolic compounds biosynthesis. The authors suggest that melatonin treatment protects peach fruit to a certain degree from chilling injury by specifically activating the biosynthesis of phenolic compounds (Gao et al., 2018). Additionally, a label-free differential proteomics analysis revealed the effect of melatonin on promoting fruit ripening and anthocyanin accumulation upon post-harvest in tomato fruits (Sun et al., 2016). The authors reported that exogenous melatonin increased eight enzymes related to the anthocyanin pathway including inter alia flavonol-3-hydroxylase, flavanone 3 beta-hydroxylase, anthocyanidin synthase/leucoanthocyanidin dioxygenase, and anthocyanidin 3-O-glucosyltransferase. Moreover, post-harvest treatment with melatonin increased total phenols and anthocyanins in strawberry fruits (Aghdam and Fard, 2016), and delayed loss of total phenols, flavonoids and anthocyanins in litchi fruits (Zhang et al., 2018). Treatments with melatonin increased the contents of phenols, anthocyanins and flavonoids in grape berries (Xu et al., 2017). Additionally, melatonin has been reported to enhance lycopene accumulation and ethylene production in tomatoes, suggesting that melatonin may increase the content of lycopene by impacting ethylene biosynthesis and signaling (Sun et al., 2015). The participation of ethylene in the melatonin-induced regulation of bioactive compounds has also been observed in grape berries, where double block treatment of ethylene showed reduced effects of melatonin on polyphenol contents (Xu et al., 2017).

\section{CONCLUSION}

It is concluded that chorismate-derived phytohormones, including auxin, SA and melatonin, not only share a common precursor but play essential roles in the regulation of fruit growth and ripening. A metabolic and functional cross-talk between them and with other phytohormones occurs in a spatiotemporal manner to finely regulate the development of climacteric and 
non-climacteric fruits. The differences in the dynamics within climacteric and non-climacteric fruits evidence that the response of chorismate-derived hormones is not universal but rather strongly species-specific. Furthermore, chorismate-derived phytohormones also modulate the accumulation of bioactive compounds, thus influencing fruit quality. Further research is, however, needed to better understand how (i) other hormones, such as ethylene and ABA, modulate their biosynthesis studying key metabolic diversion points, (ii) they interact at the functional and molecular levels, and (iii) they jointly modulate bioactive compounds biosynthesis and consequently influence not only fruit growth and ripening, but also the quality of climacteric and non-climacteric fruits.

\section{REFERENCES}

Abreu, M. E., and Munné-Bosch, S. (2009). Salicylic acid deficiency in NahG transgenic lines and sid2 mutants increases seed yield in the annual plant Arabidopsis thaliana. J. Exp. Bot. 60, 1261-1271. doi: 10.1093/jxb/ern363

Aghdam, M. S., Asghari, M., Khorsandi, O., and Mohayeji, M. (2014). Alleviation of postharvest chilling injury of tomato fruit by salicylic acid treatment. J. Food Sci. Technol. 51, 2815-2820. doi: 10.1007/s13197-012-0757-1

Aghdam, M. S., and Fard, J. R. (2016). Melatonin treatment attenuates postharvest decay and maintains nutritional quality of strawberry fruits (Fragaria $\mathrm{x}$ anannasa cv. Selva) by enhancing GABA shunt activity. Food Chem. 221, 1650-1657. doi: 10.1016/j.foodchem.2016.10.123

Aghdam, M. S., Luo, Z., Jannatizadeh, A., Sheikh-Assadi, M., Sharafi, Y., Farmani, B., et al. (2019). Employing exogenous melatonin applying confers chilling tolerance in tomato fruits by upregulating ZAT2/6/122/6/12 giving rise to promoting endogenous polyamines, proline, and nitric oxide accumulation by triggering arginine pathway activity. Food Chem. 275, 549-556. doi: 10.1016/ j.foodchem.2018.09.157

Arnao, M. B., and Hernández-Ruiz, J. (2015). "Melatonin: synthesis from tryptophan and its role in higher plants," in Amino Acids in Higher Plants, ed. J. P. F. D’ Mello (Boston, CA: CAB International), 390-435. doi: 10.1079/ 9781780642635.0390

Arnao, M. B., and Hernández-Ruiz, J. (2018). Melatonin and its relationship to plant hormones. Ann. Bot. 121, 195-207. doi: 10.1093/aob/mcx114

Asghari, M., and Aghdam, M. S. (2010). Impact of salicylic acid on postharvest physiology of horticultural crops. Trends Food Sci. Technol. 21, 502-509. doi: 10.1016/j.tifs.2010.07.009

Babalar, M., Asghari, M., Talaei, A., and Khosroshahi, A. (2007). Effect of preand postharvest salicylic acid treatment on ethylene production, fungal decay and overall quality of Selva strawberry fruit. Food Chem. 105, 449-453. doi: 10.1016/j.foodchem.2007.03.021

Barry, C. S., and Giovannoni, J. J. (2007). Ethylene and fruit ripening. J. Plant Growth Regul. 26, 143-159. doi: 10.1007/s00344-007-9002-y

Bermejo, A., Granero, B., Mesejo, C., Reig, C., Tejedo, V., Agustí, M., et al. (2018). Auxin and gibberellin interact in citrus fruit set. J. Plant Growth Regul. 37, 491-501. doi: 10.1007/s00344-017-9748-9

Bernales, M., Monsalve, L., Ayala-Raso, A., Valdenegro, M., Martínez, J. P., Travisany, D., et al. (2019). Expression of two indole-3-acetic acid (IAA)-amido synthetase (GH3) genes during fruit development of raspberry (Rubus idaeus Heritage). Sci. Hortic. 246, 168-175. doi: 10.1016/j.scienta.2018.09.077

Björkman, M., Klingen, I., Birch, A. N., Bones, A. M., Bruce, T. J., Johansen, T. J., et al. (2011). Phytochemicals of Brassicaceae in plant protection and human health - Influences of climate, environment and agronomic practice. Phytochemistry 72, 538-556. doi: 10.1016/j.phytochem.2011.01.014

Böttcher, C., Boss, P. K., and Davies, C. (2011). Acyl substrate preferences of an IAA-amido synthetase account for variations in grape (Vitis vinifera L.) berry ripening caused by different auxinic compounds indicating the importance of auxin conjugation in plant development. J. Exp. Bot. 62, 4267-4280. doi: $10.1093 / \mathrm{jxb} / \mathrm{err} 134$

\section{AUTHOR CONTRIBUTIONS}

SM-B conceived and designed the review with the help of MP-L. MP-L, PM, MM, and SM-B wrote the manuscript. MP-L prepared figures with the help of PM. All authors contributed to the discussion of ideas, revised and approved the final manuscript.

\section{FUNDING}

This work was funded by an ICREA Academia award given to SM-B by the Catalan Government.

Böttcher, C., Burbidge, C. A., Boss, P. K., and Davies, C. (2013). Interactions between ethylene and auxin are crucial to the control of grape (Vitis vinifera L.) berry ripening. BMC Plant Biol. 13:222. doi: 10.1186/1471-2229-13-222

Böttcher, C., Keyzers, R. A., Boss, P. K., and Davies, C. (2010). Sequestration of auxin by the indole-3-acetic acid-amido synthetase GH3-1 in grape berry (Vitis vinifera L.) and the proposed role of auxin conjugation during ripening. J. Exp. Bot. 61, 3615-3625. doi: 10.1093/jxb/erq174

Breitel, D. A., Chappell-Maor, L., Meir, S., Panizel, I., Puig, C. P., Hao, Y., et al. (2016). AUXIN RESPONSE FACTOR 2 intersects hormonal signals in the regulation of tomato fruit ripening. PLoS Genet. 12:e1005903. doi: 10.1371/ journal.pgen.1005903

Busatto, N., Salvagnin, U., Resentini, F., Quaresimin, S., Navazio, L., Marin, O., et al. (2017). The peach RGF/GLV signaling peptide pCTG134 is involved in a regulatory circuit that sustains auxin and ethylene actions. Front. Plant Sci. 11:1711. doi: 10.3389/fpls.2017.01711

Byeon, Y., Park, S., Kim, Y.-S., Park, D.-H., Lee, S., and Back, K. (2012). Lightregulated melatonin biosynthesis in rice during the senescence process in detached leaves. J. Pineal Res. 5, 107-111. doi: 10.1111/j.1600-079X.2012. 00976.x

Byeon, Y., Park, S., Lee, H. Y., Kim, Y. S., and Back, K. (2014). Elevated production of melatonin in transgenic rice seeds expressing rice tryptophan decarboxylase. J. Pineal Res. 56, 275-282. doi: 10.1111/jpi.12120

Cao, J. K., Yan, J. Q., Zhao, Y. M., and Jiang, W. B. (2013). Effects of four preharvest foliar sprays with $\beta$-aminobutyric acid or salicylic acid on the incidence of postharvest disease and induced defence responses in jujube (Zizyphus jujuba Mill.) fruit after storage. J. Hortic. Sci. Biotechnol. 88, 338-344. doi: 10.1080/14620316. 2013.11512974

Cao, S., Shao, J., Shi, L., Xu, L., Shen, Z., Chen, W., et al. (2018). Melatonin increases chilling tolerance in postharvest peach fruit by alleviating oxidative damage. Sci. Rep. 8:806. doi: 10.1038/s41598-018-19363-5

Carswell, G. K., Johnson, C. M., Shillito, R. D., and Harms, C. T. (1989). O-acetylsalicylic acid promotes colony formation from protoplasts of an elite maize inbred. Plant Cell Rep. 8, 282-284. doi: 10.1007/BF00274130

Castellarin, S. D., Gambetta, G. A., Wada, H., Shackel, K. A., and Matthews, M. A. (2011). Fruit ripening in Vitis vinifera: spatiotemporal relationships among turgor, sugar accumulation, and anthocyanin biosynthesis. J. Exp. Bot. 62, 4345-4354. doi: 10.1093/jxb/err150

Catinot, J., Buchala, A., Abou-Mansour, E., and Métraux, J.-P. (2008). Salicylic acid production in response to biotic and abiotic stress depends on isochorismate in Nicotiana benthamiana. FEBS Lett. 582, 473-478. doi: 10.1016/j.febslet.2007. 12.039

Chen, J., Mao, L., Lu, W., Ying, T., and Luo, Z. (2016). Transcriptome profiling of postharvest strawberry fruit in response to exogenous auxin and abscisic acid. Planta 243, 183-197. doi: 10.1007/s00425-0152402-5

Chen, Q., Qi, W. B., Reiter, R. J., Wei, W., and Wang, B. M. (2009). Exogenously applied melatonin stimulates root growth and raises endogenous indoleacetic acid in roots of etiolated seedlings of Brassica juncea. J. Plant Physiol. 166, 324-328. doi: 10.1016/j.jplph.2008.06.002 
Chen, X., Sun, C., Laborda, P., Zhao, Y., Palmer, I., Fu, Z. Q., et al. (2018). Melatonin treatment inhibits the growth of Xanthomonas oryzae pv. oryzaezae. Front. Microbiol. 9:2280. doi: 10.3389/fmicb.2018.02280

Choudhury, S. R., Roy, S., and Sengupta, D. N. (2008). Characterization of transcriptional profiles of MA-ACS1 and MA-ACO1 genes in response to ethylene, auxin, wounding, cold and different photoperiods during ripening in banana fruit. J. Plant Physiol. 165, 1865-1878. doi: 10.1016/j.jplph.2008.04.012

Croteau, R., Kutchan, T. M., and Lewis, N. G. (2000). "Natural products (secondary metabolites)," in Biochemistry \& Molecular Biology of Plants: Chemistry \& Molecular Biology of Plants, eds B. Buchanan, W. Gruissem, and R. Jones (Rockville, MD: ASPP), 1250-1318.

Daood, H. G., Vinkler, M., Márkus, F., Hebshi, A., and Biacs, P. A. (1996). Antioxidant vitamin content of spice red pepper (paprika) as affected by technological and varietal factors. Food Chem. 55, 365-372. doi: 10.1016/03088146(95)00136-0

Davies, C., Boss, P. K., and Robinson, S. P. (1997). Treatment of grape berries, a nonclimacteric fruit with a synthetic auxin, retards ripening and alters the expression of developmentally regulated genes. Plant Physiol. 115, 1155-1161. doi: $10.1104 /$ pp.115.3.1155

De Luca, V., Marineau, C., and Brisson, N. (1989). Molecular cloning and analysis of cDNA encoding a plant tryptophan decarboxylase: comparison with animal dopa decarboxylases. Proc. Natl. Acad. Sci.U.S.A. 86, 2582-2586. doi: 10.1073/ pnas.86.8.2582

Dokhanieh, A. Y., Aghdam, M. S., Fard, J. R., and Hassanpour, H. (2013). Postharvest salicylic acid treatment enhances antioxidant potential of cornelian cherry fruit. Sci. Hortic. 154, 31-36. doi: 10.1016/j.scienta.2013.01.025

Dong, C. J., Li, L., Shang, Q. M., Liu, X. Y., and Zhang, Z. G. (2014). Endogenous salicylic acid accumulation is required for chilling tolerance in cucumber (Cucumis sativus L.) seedlings. Planta 240, 687-700. doi: 10.1007/s00425-0142115-1

Dumas, Y., Dadomo, M., Di Lucca, G., and Grolier, P. (2003). Effects of environmental factors and agricultural techniques on antioxidant content of tomatoes. J. Sci. Food Agric. 83, 369-382. doi: 10.1002/jsfa.1370

Eberhard, S., Doubrava, N., Marfa, V., Mohnen, D., Southwick, A., Darvill, A., et al. (1989). Pectic cell wall fragments regulate tobacco thin-cell-layer explant morphogenesis. Plant Cell 1, 747-755. doi: 10.1105/tpc.1.8.747

El-Sharkawy, I., Sherif, S. M., Jones, B., Mila, I., Kumar, P. P., Bouzayen, M., et al. (2014). TIR1-like auxin-receptors are involved in the regulation of plum fruit development. J. Exp. Bot. 65, 5205-5215. doi: 10.1093/jxb/ eru279

Enríquez-Valencia, A. J., Vázquez-Flota, F. A., Ku-Cauich, J. R., and EscobedoGarciaMedrano, R. M. (2018). Differentially expressed genes during the transition from early to late development phases in somatic embryo of banana (Musa spp. AAB group, Silk subgroup) cv. Manzano. Plant Cell Tissue Organ Cult. 136, 289-302. doi: 10.1007/s11240-018-1514-6

Estrada-Johnson, E., Csukasi, F., Pizarro, C. M., Vallarino, J. G., Kiryakova, Y., Vioque, A., et al. (2017). Transcriptomic analysis in strawberry fruits reveals active auxin biosynthesis and signaling in the ripe receptacle. Front. Plant Sci. 8:889. doi: 10.3389/fpls.2017.00889

Feng, X., Wang, M., Zhao, Y., Han, P., and Dai, Y. (2014). Melatonin from different sources, functional roles, and analytical methods. Trends Food Sci. Technol. 37, 21-31. doi: 10.1016/j.tifs.2014.02.001

Fraser, P. D., Truesdale, M. R., Bird, C. R., Schuch, W., and Bramley, P. M. (1994). Carotenoid biosynthesis during tomato fruit development evidence for tissuespecific gene expression. Plant Physiol. 105, 405-413. doi: 10.1104/pp.105. 1.405

Gao, H., Lu, Z., Yang, Y., Wang, S., Yang, T., Cao, M., et al. (2018). Melatonin treatment reduces chilling injury in peach fruit through its regulation of membrane fatty acid contents and phenolic metabolism. Food Chem. 245, 659-666. doi: 10.1016/j.foodchem.2017.10.008

Garcion, C., Lohmann, A., Lamodière, E., Catinot, J., Buchala, A., Doermann, P., et al. (2008). Characterization and biological function of the ISOCHORISMATE SYNTHASE2 gene of Arabidopsis. Plant Physiol. 147, 1279-1287. doi: 10.1104/ pp.108.119420

Giménez, M. J., Serrano, M., Valverde, J. M., Martínez-Romero, D., Castillo, S., Valero, D., et al. (2017). Preharvest salicylic acid and acetylsalicylic acid treatments preserve quality and enhance antioxidant systems during postharvest storage of sweet cherry cultivars. J. Sci. Food Agric. 97, 1220-1228. doi: $10.1002 /$ jsfa.7853

Giménez, M. J., Valverde, J. M., Valero, D., Díaz-Mula, H. M., Zapata, P. J., Serrano, M., et al. (2015). Methyl salicylate treatments of sweet cherry trees improve fruit quality at harvest and during storage. Sci. Hortic. 197, 665-673. doi: 10.1016/j.scienta.2015.10.033

Giménez, M. J., Valverde, J. M., Valero, D., Guillén, F., Martínez-Romero, D., Serrano, M., et al. (2014). Quality and antioxidant properties on sweet cherries as affected by preharvest salicylic and acetylsalicylic acids treatments. Food Chem. 160, 226-232. doi: 10.1016/j.foodchem.2014.03.107

Glowacz, M., Bill, M., Tinyane, P. P., and Sivakumar, D. (2017). Maintaining postharvest quality of cold stored 'Hass' avocados by altering the fatty acids content and composition with the use of natural volatile compounds - methyl jasmonate and methyl salicylate. J. Sci. Food. Agric. 97, 5186-5193. doi: 10.1002/ jsfa. 8400

Gouthu, S., and Deluc, L. G. (2015). Timing of ripening initiation in grape berries and its relationship to seed content and pericarp auxin levels. BMC Plant Biol. 15:46. doi: 10.1186/s12870-015-0440-6

Hernández-Ruiz, J., Cano, A., and Arnao, M. B. (2005). Melatonin acts as a growthstimulating compound in some monocot species. J. Pineal Res. 39, 137-142. doi: 10.1111/j.1600-079X.2005.00226.x

$\mathrm{Hu}$, J., Israeli, A., Ori, N., and Suna, T. P. (2018). The Interaction between DELLA and ARF/IAA mediates crosstalk between gibberellin and auxin signaling to control fruit initiation in tomato. Plant Cell 30, 1710-1728. doi: 10.1105/tpc. 18.00363

Hu, W., Yang, H., Tie, W., Yan, Y., Ding, Z., Liu, Y., et al. (2017). Natural variation in banana varieties highlights the role of melatonin in postharvest ripening and quality. J. Agric. Food Chem. 65, 9987-9994. doi: 10.1021/acs.jafc.7b03354

Jia, H., Jiu, S., Zhang, C., Wang, C., Tariq, P., Liu, Z., et al. (2016). Abscisic acid and sucrose regulate tomato and strawberry fruit ripening through the abscisic acid-stress-ripening transcription factor. Plant Biotechnol. J. 14, 2045-2065. doi: $10.1111 /$ pbi. 12563

Johnson, E. J. (2002). The role of carotenoids in human health. Nutr. Clin. Carer 5, 56-65. doi: 10.1046/j.1523-5408.2002.00004.x

Kang, S., Kang, K., Lee, K., and Back, K. (2007). Characterization of rice tryptophan decarboxylases and their direct involvement in serotonin biosynthesis in transgenic rice. Planta 227, 263-272. doi: 10.1007/s00425-007-0614-z

Kolář, J., Macháčková, I., Eder, J., Prinsen, E., van Dongen, W., van Onckelen H., et al. (1997). Melatonin: occurrence and daily rhythm in Chenopodium rubrum. Phytochemistry 44, 1407-1413. doi: 10.1016/S0031-9422(96)00568-7

Kumar, R., Khurana, A., and Sharma, A. K. (2014). Role of plant hormones and their interplay in development and ripening of fleshy fruits. J. Exp. Bot. 65, 4561-4575. doi: 10.1093/jxb/eru277

Li, J., Khan, Z. U., Taoa, X., Maoa, L., Luoa, Z., and Yinga, T. (2017). Effects of exogenous auxin on pigments and primary metabolite profile of postharvest tomato fruit during ripening. Sci. Hortic. 219, 90-97. doi: 10.1016/j.scienta. 2017.03.011

Li, J., Tao, X., Li, L., Mao, L., Luo, Z., Khan, Z. U., et al. (2016). Comprehensive RNA-Seq analysis on the regulation of tomato ripening by exogenous auxin. PLoS One 11:e0156453. doi: 10.1371/journal.pone.0156453

Li, Y., Lua, Y., Lia, L., Chu, Z., Zhang, H., Li, H., et al. (2019). Impairment of hormone pathways results in a general disturbance of fruit primary metabolism in tomato. Food Chem. 274, 170-179. doi: 10.1016/j.foodchem.2018.08.026

Liao, X., Li, M., Liu, B., Yan, M., Yu, X., Zi, H., et al. (2018). Interlinked regulatory loops of ABA catabolism and biosynthesis coordinate fruit growth and ripening in woodland strawberry. Proc. Natl. Acad. Sci. U.S.A. 115, E11542-E11550. doi: $10.1073 /$ pnas. 1812575115

Liu, J., Zhai, R., Liu, F., Zhao, Y., Wang, H., Liu, L., et al. (2018). Melatonin induces parthenocarpy by regulating genes in gibberellin pathways of 'Starkrimson' Pear (Pyrus communis L.). Front. Plant Sci. 9:946. doi: 10.3389/fpls.2018. 00946

Liu, S., Zhang, Y., Feng, Q., Qin, L., Pan, C., Lamin-Samu, A. T., et al. (2018). Tomato AUXIN RESPONSE FACTOR 5 regulates fruit set and development via the mediation of auxin and gibberellin signaling. Sci. Rep. 8:2971. doi: 10.1038/s41598-018-21315-y

Liu, K., Yuan, C., Feng, S., Zhong, S., Li, H., Zhong, J., et al. (2017). Genome-wide analysis and characterization of $A u x / I A A$ family genes related to fruit ripening 
in papaya (Carica papaya L.). BMC Genomics18:351. doi: 10.1186/s12864-0173722-6

Liu, M., Pirrello, J., Chervin, C., Roustan, J.-P., and Bouzayen, M. (2015). Ethylene control of fruit ripening: revisiting the complex network of transcriptional regulation. Plant Physiol. 169, 2380-2390. doi: 10.1104/pp.15.01361

Liu, S., Stampfer, M. J., Hu, F. B., Giovannucci, E., Rimm, E., Manson, J. E., et al. (1999). Whole-grain consumption and risk of coronary heart disease: results from the nurses' health study. Am. J. Clin. Nutr. 70, 412-419. doi: 10.1093/ajcn/ 70.3.412

Loake, G., and Grant, M. (2007). Salicylic acid in plant defence-the players and protagonists. Curr. Opin. Plant Biol. 10, 466-472. doi: 10.1016/j.pbi.2007.08.008

Lu, Q., Zhang, W., Gao, J., Lu, M., Zhang, L., and Li, J. (2015). Simultaneous determination of plant hormones in peach based on dispersive liquidliquid microextraction coupled with liquid chromatography-ion trap mass spectrometry. J. Chromatogr. B Analyt. Technol. Biomed. Life Sci. 992, 8-13. doi: 10.1016/j.jchromb.2015.04.014

Lurie, S., and Crisosto, C. H. (2005). Chilling injury in peach and nectarine. Postharvest Biol. Technol. 37, 195-208. doi: 10.1016/j.postharvbio.2005.04.012

Martínez-Esplá, A., Zapata, P. J., Valero, D., Martínez-Romero, D., Díaz-Mula, H. M., and Serrano, M. (2017). Preharvest treatments with salicylates enhance nutrient and antioxidant compounds in plum at harvest and after storage. J. Sci. Food Agric. 98, 2742-2750. doi: 10.1002/jsfa.8770

Meng, J. F., Xu, T. F., Song, C. Z., Yu, Y., Hu, F., Zhang, L., et al. (2015). Melatonin treatment of pre-veraison grape berries to increase size and synchronicity of berries and modify wine aroma components. Food Chem. 185, 127-134. doi: 10.1016/j.foodchem.2015.03.140

Mezzetti, B., Landi, L., Pandolfini, T., and Spena, A. (2004). The defH9-iaaM auxinsynthesizing gene increases plant fecundity and fruit production in strawberry and raspberry. BMC Biotechnol. 4:4. doi: 10.1186/1472-6750-4-4

Miret, J. A., and Müller, M. (2017). "AsA/DHA redox pair influencing plant growth and stress tolerance," in Ascorbic Acid in Plant Growth, Development and Stress Tolerance Ascorbic Acid in Plant Growth, Development and Stress Tolerance, eds M. Hossain, S. Munné-Bosch, D. Burritt, P. Diaz-Vivancos, M. Fujita, and A. Lorence (Cham: Springer), 297-319.

Moro, L., Aymoto, N. M., and Purgatto, E. (2017). Postharvest auxin and methyl jasmonate effect on anthocyanin biosynthesis in red raspberry (Rubus idaeus L.). J. Plant Growth. Regul. 36, 773-782. doi: 10.1007/s00344-017-9682-x

Mueller, M., Hobiger, S., and Jungbauer, A. (2010). Anti-inflammatory activity of extracts from fruits, herbs and spices. Food Chem. 122, 987-996. doi: 10.1016/j. foodchem.2010.03.041

Oikawa, A., Otsuka, T., Nakabayashi, R., Jikumaru, Y., Isuzugawa, K., Murayama, H., et al. (2015). Metabolic profiling of developing pear fruits reveals dynamic variation in primary and secondary metabolites, including plant hormones. PLoS One 10:e0131408. doi: 10.1371/journal.pone.0131408

Onik, J. C., Hu, X., Lin, Q., and Wang, Z. (2018). Comparative transcriptomic profiling to understand pre- and post-ripening hormonal regulations and anthocyanin biosynthesis in early ripening apple fruit. Molecules 31:E1908. doi: 10.3390/molecules 23081908

Park, S., Le, T.-N. N., Byeon, Y., Kim, Y. S., and Back, K. (2013). Transient induction of melatonin biosynthesis in rice (Oryza sativa L.) during reproductive stage. J. Pineal Res. 55, 40-45. doi: 10.1111/jpi.12021

Paul, V., Pandey, R., and Srivastava, G. C. (2012). The fading distinctions between classical patterns of ripening in climacteric and non-climacteric fruit and the ubiquity of ethylene-An overview. J. Food Sci. Technol. 49, 1-21. doi: 10.1007/ s13197-011-0293-4

Ranalli, A., Tombesi, A., Ferrante, M. L., and De Mattia, G. (1998). Respiratory rate of olive drupes during their ripening cycle and quality of oil extracted. J. Sci. Food Agric. 77, 359-367. doi: 10.1002/(SICI)1097-0010(199807)77: 3<359::AID-JSFA43>3.0.CO;2-R

Reig, C., Martínez-Fuentes, A., Mesejo, C., and Agustí, M. (2018). Hormonal control of parthenocarpic fruit set in 'Rojo Brillante' persimmon (Diospyros kaki Thunb.). J. Plant Physiol. 238, 96-104. doi: 10.1016/j.jplph.2018.09.004

Reyes-Olalde, J. I., Zúñiga-Mayo, V. M., Serwatowska, J., Chavez Montes, R. A., Lozano-Sotomayor, P., Herrera-Ubaldo, H., et al. (2017). The bHLH transcription factor SPATULA enables cytokinin signaling, and both activate auxin biosynthesis and transport genes at the medial domain of the gynoecium. PLoS Genet. 13:e1006726. doi: 10.1371/journal.pgen. 1006726
Rodrigo, M. J., Alquezar, B., and Zacarías, L. (2006). Cloning and characterization of two 9-cis-epoxycarotenoid dioxygenase genes, differentially regulated during fruit maturation and under stress conditions, from orange (Citrus sinensis L. Osbeck). J. Exp. Bot. 57, 633-643. doi: 10.1093/jxb/erj048

Sayyari, M., Castillo, S., Valero, D., Díaz-Mula, H. M., and Serrano, M. (2011). Acetylsalicylic acid alleviates chilling injury and maintains nutritive and bioactive compounds and antioxidant activity during postharvest storage of pomegranates. Postharvest Biol. Technol. 60, 136-142. doi: 10.1016/j. postharvbio.2010.12.012

Serrani, J. C., Carrera, E., Ruiz-Rivero, O., Gallego-Giraldo, L., Pereira, L. E., and García-Martínez, J. L. (2010). Inhibition of auxin transport from the ovary or from the apical shoot induces parthenocarpic fruit-set in tomato mediated by gibberellins. Plant Physiol. 153, 851-862. doi: 10.1104/pp.110.155424

Sharif, R., Xie, C., Zhang, H., Arnao, M. B., Ali, M., Ali, Q., et al. (2018). Melatonin and its effects on plant systems. Molecules 23:E2352. doi: 10.3390/ molecules23092352

Shi, H., Wang, Y., Qui, A., Zhang, Y., Xu, J., Wang, A., et al. (2013). PpACS1b, a pear gene encoding ACC synthase, is regulated during fruit late development and involved in response to salicylic acid. Sci. Hortic. 164, 602-609. doi: 10. 1016/j.scienta.2013.09.055

Shi, H. Y., and Zhang, Y. X. (2012). Pear ACO genes encoding putative 1aminocyclopropane-1-carboxylate oxidase homologs are functionally expressed during fruit ripening and involved in response to salicylic acid. Mol. Biol. Rep. 39, 9509-9519. doi: 10.1007/s11033-012-1815-5

Shi, H. Y., and Zhang, Y. X. (2014). Expression and regulation of pear 1aminocyclopropane-1-carboxylic acid synthase gene (PpACS1a) during fruit ripening, under salicylic acid and indole-3-acetic acid treatment, and in diseased fruit. Mol. Biol. Rep. 41, 4147-4154. doi: 10.1007/s11033-0143286-3

Singh, R. K., Ali, S. A., Nath, P., and Sane, V. A. (2011). Activation of ethyleneresponsive hydroxyphenylpyruvate dioxygenase leads to increased tocopherol levels during ripening in mango. J. Exp. Bot. 62, 3375-3385. doi: 10.1093/jxb/ err006

Sravankumar, T., Akash, Naik, N., and Kumar, R. (2018). A ripening-induced SlGH3-2 gene regulates fruit ripening via adjusting auxin-ethylene levels in tomato (Solanum lycopersicum L.). Plant Mol. Biol. 98, 455-469. doi: 10.1007/ s11103-018-0790-1

Srivastava, K. M., and Dwivedi, U. N. (2000). Delayed ripening of banana fruit by salicylic acid. Plant Sci. 158, 87-96. doi: 10.1016/S0168-9452(00)00304-6

Sturgeon, S. R., and Ronnenberg, A. G. (2010). Pomegranate and breast cancer: possible mechanisms of prevention. Nutr. Rev. 68, 122-128. doi: 10.1111/j. 1753-4887.2009.00268.x

Su, L., Diretto, G., Purgatto, E., Danoun, S., Zouine, M., Li, Z., et al. (2015). Carotenoid accumulation during tomato fruit ripening is modulated by the auxin-ethylene balance. BMC Plant Biol. 15:114. doi: 10.1186/s12870-0150495-4

Sun, Q., Zhang, N., Wang, J., Cao, Y., Li, X., Zhang, H., et al. (2016). A label-free differential proteomics analysis reveals the effect of melatonin on promoting fruit ripening and anthocyanin accumulation upon postharvest in tomato. $J$ Pineal Res. 61, 138-153. doi: 10.1111/jpi.12315

Sun, Q., Zhang, N., Wang, J., Zhang, H., Li, D., Shi, J., et al. (2015). Melatonin promotes ripening and improves quality of tomato fruit during postharvest life. J. Exp. Bot. 66, 657-668. doi: 10.1093/jxb/eru332

Symons, G. M., Chua, Y. J., Ross, J. J., Quittenden, L. J., Davies, N. W., and Reid, J. B. (2012). Hormonal changes during non-climacteric ripening in strawberry. J. Exp. Bot. 63, 695-709. doi: 10.1093/jxb/ers147

Tadiello, A., Longhi, S., Moretto, M., Ferrarini, A., Tononi, P., Farneti, B., et al. (2016a). Interference with ethylene perception at receptor level sheds light on auxin and transcriptional circuits associated with the climacteric ripening of apple fruit (Malus x domestica Borkh.). Plant J. 88, 963-975. doi: 10.1111/tpj. 13306

Tadiello, A., Ziosi, V., Negri, A. S., Noferini, M., Fiori, G., Busatto, N., et al. (2016b). On the role of ethylene, auxin and a GOLVEN-like peptide hormone in the regulation of peach ripening. BMC Plant Biol. 16:44. doi: 10.1186/s12870-0160730- 7

Tapiero, H., Townsend, D. M., and Tew, K. D. (2004). The role of carotenoids in the prevention of human pathologies. Biomed. Pharmacother. 58, 100-110. doi: 10.1016/j.biopha.2003.12.006 
Tatsuki, M., Nakajima, N., Fujii, H., Shimada, T., Nakano, M., Hayashi, K., et al. (2013). Increased levels of IAA are required for system 2 ethylene synthesis causing fruit softening in peach (Prunus persica L. Batsch). J. Exp. Bot. 64, 1049-1059. doi: 10.1093/jxb/ers381

Taylor-Teeples, M., Lanctot, A., and Nemhauser, J. L. (2016). As above, so below: auxin's role in lateral organ development. Dev. Biol. 419, 156-164. doi: 10.1016/ j.ydbio.2016.03.020

Teribia, N., Tijero, V., and Munné-Bosch, S. (2016). Linking hormonal profiles with variations in sugar and anthocyanin contents during the natural development and ripening of sweet cherries. N. Biotechnol. 33, 824-833. doi: 10.1016/j.nbt.2016.07.015

Uppalapati, S. R., Ishiga, Y., Wangdi, T., Kunkel, B. N., Anand, A., Mysore, K. S., et al. (2007). The phytotoxin coronatine contributes to pathogen fitness and is required for suppression of salicylic acid accumulation in tomato inoculated with Pseudomonas syringae pv. tomato DC3000. Mol. Plant Microbe Interact. 20, 955-965. doi: 10.1094/MPMI-20-8-0955

Valero, D., Díaz-Mula, H. M., Zapata, P. J., Castillo, S., Guillén, F., MartínezRomero, D., et al. (2011). Postharvest treatments with salicylic acid, acetylsalicylic acid or oxalic acid delayed ripening and enhanced bioactive compounds and antioxidant capacity in sweet cherry. J. Agric. Food Chem. 59, 5483-5489. doi: 10.1021/jf200873j

Vasconsuelo, A., and Boland, R. (2007). Molecular aspects of the early stages of elicitation of secondary metabolites in plants. Plant Sci. 172, 861-875. doi: 10.1016/j.plantsci.2007.01.006

Wang, C., Yin, L.-Y., Shi, X.-Y., Xiao, H., Kang, K., Liu, X.-Y., et al. (2016). Effect of cultivar, temperature, and environmental conditions on the dynamic change of melatonin in Mulberry fruit development and wine fermentation. J. Food Sci. 81, M958-M967. doi: 10.1111/1750-3841.13263

Wang, H., Jones, B., Li, Z., Frasse, P., Delalande, C., Regad, F., et al. (2005). The tomato Aux/IAA transcription factor IAA9 is involved in fruit development and leaf morphogenesis. Plant Cell 17, 2676-2692. doi: 10.1105/tpc.105.033415

Wang, Z., Ma, L., Zhang, X., Xu, L., Cao, J., and Jiang, W. (2015). The effect of exogenous salicylic acid on antioxidant activity, bioactive compounds and antioxidant system in apricot fruit. Sci. Hortic. 181, 113-120. doi: 10.1016/j. scienta.2014.10.055

Wani, A. B., Chadar, H., Wani, A. H., Singh, S., and Upadhyay, N. (2017). Salicylic acid to decrease plant stress. Enviorn. Chem. Lett. 15, 101-123. doi: 10.1007/ s10311-016-0584-0

Wei, Y., Liu, G., Chang, T., Lin, D., Reiter, R. J., He, C., et al. (2018). Melatonin biosynthesis enzymes recruit WRKY transcription factors to regulate melatonin accumulation and transcriptional activity on W-box in cassava. J. Pineal Res. 65:e12487. doi: 10.1111/jpi.12487

Wen, D., Gong, B., Sun, S., Liu, S., Wang, X., Wei, M., et al. (2016). Promoting roles of melatonin in adventitious root development of Solanum lycopersicum L. by regulating auxin and nitric oxide signaling. Front. Plant Sci. 7:718. doi: 10.3389/fpls. 2016.00718

Wildermuth, M. C., Dewdney, J., Wu, G., and Ausubel, F. M. (2001). Isochorismate synthase is required to synthesize salicylic acid for plant defence. Nature 414, 562-565. doi: 10.1038/35107108

Xu, L., Yue, Q., Bian, F., Sun, H., Zhai, H., and Yao, Y. (2017). Melatonin enhances phenolics accumulation partially via ethylene signaling and resulted in high antioxidant capacity in grape berries. Front. Plant Sci. 8:1426. doi: 10.3389/fpls. 2017.01426

Xu, L., Yue, Q., Xiang, G., Bian, F., and Yao, Y. (2018). Melatonin promotes ripening of grape berry via increasing the levels of $\mathrm{ABA}, \mathrm{H} 2 \mathrm{O} 2$, and particularly ethylene. Hortic. Res. 5:41. doi: 10.1038/s41438-018-0045-y

Zaharah, S. S., Singh, Z., Symons, G. M., and Reid, J. B. (2012). Role of brassinosteroids, ethylene, abscisic acid, and indole-3- acetic acid in mango fruit ripening. J. Plant Growth Regul. 31, 363-372. doi: 10.1007/s00344-0119245-5

Zeng, W., and He, S. Y. (2010). A prominent role of the flagellin receptor FLAGELLIN-SENSING2 in mediating stomatal response to Pseudomonas syringae pv tomato DC3000 in Arabidopsis. Plant Physiol. 153, 1188-1198. doi: 10.1104/pp.110.157016

Zhai, R., Liu, J., Liu, F., Zhao, Y., Liu, L., Fang, C., et al. (2018). Melatonin limited ethylene production, softening and reduced physiology disorder in pear (Pyrus communis L.) fruit during senescence. Postharvest Biol. Technol. 139, 38-46. doi: 10.1016/j.postharvbio.2018.01.017

Zhang, H., Chen, L., Zhao, L., Zheng, X., Yang, Q., and Zhang, X. (2017). Investigating proteome and transcriptome defence response of apples induced by Yarrowia lipolytica. Mol. Plant Microbe Interact. 30, 301-311. doi: 10.1094/ MPMI-09-16-0189-R

Zhang, Y., Chen, K., Zhang, S., and Ferguson, I. (2003). The role of salicylic acid in postharvest ripening of kiwifruit. Postharvest Biol. Technol. 28, 67-74. doi: 10.1016/S0925-5214(02)00172-2

Zhang, Y., Huber, D. J., Hu, M., Jiang, G., Gao, Z., Xu, X., et al. (2018). Delay of postharvest browning in litchi fruit by melatonin via the enhancing of antioxidative processes and oxidation repair. J. Agric. Food Chem. 66, 74757484. doi: 10.1021/acs.jafc.8b0192

Zhao, Y., Tan, D. X., Lei, Q., Chen, H., Wang, L., Li, Q., et al. (2013). Melatonin and its potential biological functions in the fruits of sweet cherry. J. Pineal Res. 55, 79-88. doi: 10.1111/jpi.12044

Zhu, Z., Ding, Y., Zhao, J., Nie, Y., Zhang, Y., Sheng, J., et al. (2016). Effects of postharvest gibberellic acid treatment on chilling tolerance in cold-stored tomato (Solanum lycopersicum L.) fruit. Food Bioproc. Tech. 9, 1202-1209. doi: 10.1007/s11947-016-1712-3

Zuo, B., Zheng, X., He, P., Wang, L., Lei, Q., Feng, C., et al. (2014). Overexpression of MzASMT improves melatonin production and enhances drought tolerance in transgenic Arabidopsis thaliana plants. J. Pineal Res. 57, 408-417. doi: 10. $1111 /$ jpi. 1218

Conflict of Interest Statement: The authors declare that the research was conducted in the absence of any commercial or financial relationships that could be construed as a potential conflict of interest.

Copyright (C) 2019 Pérez-Llorca, Muñoz, Müller and Munné-Bosch. This is an openaccess article distributed under the terms of the Creative Commons Attribution License (CC BY). The use, distribution or reproduction in other forums is permitted, provided the original author(s) and the copyright owner(s) are credited and that the original publication in this journal is cited, in accordance with accepted academic practice. No use, distribution or reproduction is permitted which does not comply with these terms. 